EXTENDED REPORT

\title{
Salivary gland and peripheral blood T helper 1 and 2 cell activity in Sjögren's syndrome compared with non-Sï̈gren's sicca syndrome
}

\author{
J M van Woerkom, A A Kruize, M J G Wenting - van Wijk, E Knol, I C Bihari, \\ J W G Jacobs, J W J Bijlsma, F P J G Lafeber, J A G van Roon
}

See end of article for authors' affiliations

\section{Correspondence to:} Mr J M van Woerkom, Department of Rheumatology and Clinical Immunology, University Medical Centre Utrecht, The Netherlands, PO Box 85500, 3508 GA Utrecht, The Netherlands; j.vanwoerkom@azu.nl

Accepted 15 March 2005 Published Online First 7 April 2005
Objectives: To investigate whether differences in Thelper (Th) 1 and Th2 cell activity in salivary glands ("local") or ("peripheral") blood can discriminate between Siögren's syndrome (SS) and non-Siögren's sicca syndrome (nSS-sicca). Additionally, to study relationships of local and peripheral Th cell activities with each other and with disease activity measures.

Methods: 62 sicca patients (32 with SS, 30 with nSS-sicca) were studied. Local Th1 (interferon $\gamma$ (IFN $\gamma$ )) and Th2 (interleukin (IL) 4) activity were determined using immunohistochemistry. T cell production of IFN $\gamma$ and IL4 in peripheral blood (PB) was determined by ELISA. Erythrocyte sedimentation rate (ESR) and serum $\lg G$ were considered disease activity measures.

Results: ESR and serum IgG were higher in patients with SS than in patients with nSS-sicca. Local Th1 cell activity was higher and PB Th1 activity lower in patients with SS than in those with nSS-sicca. Th2 cell activity did not differ significantly between the patient groups. The ratio IFN $\gamma /$ IL4 was higher in salivary glands and lower in PB in patients with SS than in patients with nSS-sicca. Local and peripheral Th1 and Th2 cell activities correlated with ESR and serum lgG levels. ESR, serum IgG, and local or peripheral Th1 or Th2 cell activity did not discriminate between patients with SS and nSS-sicca.

Conclusions: An imbalance between Th1 and Th2 activity in sicca patients is clearly related to the severity of disease, but cannot be used to distinguish between patients with SS and those with nSS-sicca.
$\mathrm{S}$ jögren's syndrome (SS) is an autoimmune exocrinopathy primarily affecting lachrymal and salivary glands (SGs), characterised by keratoconjunctivitis sicca and xerostomia. It may occur in the absence (primary SS (pSS)) or presence of another systemic autoimmune disease, including rheumatoid arthritis (RA) and systemic lupus erythematosus (SLE) (secondary SS (sSS)).

A distinction between pSS and non-Sjögren's sicca syndrome (nSS-sicca) is considered to be helpful in defining prognosis, because patients with pSS have an increased risk for the development of extraglandular autoimmune manifestations and malignant lymphoma. ${ }^{1}$

In clinical practice this distinction may be difficult because patients with nSS-sicca may present with systemic symptoms, serological abnormalities, systemic characteristics of inflammation (raised erythrocyte sedimentation rate (ESR) and serum $\operatorname{IgG}$ ), and unspecific sialadenitis of the SGs. Moreover, patients with nSS-sicca might develop SS later in life. $^{2}$ A more detailed evaluation of the disturbed immune system might provide tools to evaluate this apparent overlap between patients with SS and nSS-sicca.

Of the lymphocytes infiltrating the SGs in patients with SS, $45-50 \%$ are of the Thelper/inducer (CD4+) phenotype, $20 \%$ of the T suppressor/cytotoxic (CD8+) phenotype, and about 20\% are B cells. ${ }^{3}$ T helper (Th) cells can be divided into at least two functionally different subsets based on the cytokines they produce: Thl cells predominantly produce proinflammatory cytokines such as interferon $\gamma$ (IFN $\gamma$ ) and interleukin (IL) 2, whereas Th2 cells predominantly produce anti-inflammatory and regulatory cytokines such as IL4, IL10, and IL13.

A disturbed Th1/Th2 cell balance has been shown to be important in the regulation of many chronic inflammatory disorders. ${ }^{5}$ It is suggested that this Th1/Th2 cell imbalance might also have a role in the pathogenesis of SS; although several studies have evaluated cytokine profiles in SS, only a limited number of studies (with relatively small numbers of patients included) have focused on this Th1/Th2 cytokine balance in SS. These studies have focused on either the SGs ("local"367) or the blood lymphocyte ("peripheral"89) compartment. Although some of these studies have included healthy control groups, none of them have compared patients with nSS-sicca with patients with SS. Therefore, we investigated in SGs and peripheral blood (PB) whether differences in Th1 and Th2 cell activity could discriminate between SS and nSS-sicca. Moreover, we investigated how local and peripheral Th activities were related to each other and with disease activity measures.

Finally, Th1 and Th2 profiles in patients with pSS with or without extraglandular manifestations and serum autoantibodies were studied; Th profiles were also correlated with the grade of labial SG infiltration.

\section{PATIENTS AND METHODS \\ Patients}

Sixty two sicca patients referred to our university hospital outpatient clinic between 1997 and 1998 were included. Routine diagnostic procedures (including medical history, physical examination, Schirmer-1 test, laboratory investigations, and labial SG biopsy) were performed. Thirty two

Abbreviations: DMEM, Dulbecco's modified Eagle's medium; ESR, erythrocyte sedimentation rate; IFN $\gamma$, interferon $\gamma$; IL, interleukin; nSSsicca, non-Siögren's sicca syndrome; PB, peripheral blood; PBS, phosphate buffered saline; pSS, primary Siögren's syndrome; RA, rheumatoid arthritis; SG, salivary gland; SLE, systemic lupus erythematosus; SS, Sjögren's syndrome; sSS, secondary Siögren's syndrome; Th, T helper 
patients met the revised European classification criteria for SS according to the American-European consensus group, ${ }^{10}$ six of them had sSS (four patients with RA and two with SLE); 30 patients were classified as having nSS-sicca. No relevant differences were found between the patients with pSS $(n=26)$ and the patients with sSS $(n=6)$, consequently they were analysed as one group.

The study was performed according to the medical ethical regulations of the Utrecht University Medical Centre; all patients gave informed consent to use a part of their labial SG tissue for research purposes. PB samples were collected on the same day within 10 minutes before the SG biopsy.

\section{Measures of disease activity}

Serum IgG and ESR, determined by standard hospital procedures, were considered representative measures of disease activity.

\section{Local Th 1 and Th2 cell activity}

As a measure of Th1 and Th2 cell activity the numbers of IFN $\gamma$ positive and IL4 positive cells, respectively, were determined in labial SG biopsy specimens. Part of each labial SG biopsy specimen was fixed and embedded in paraffin for routine diagnostic procedures (classification), and the remainder was snap frozen in Tissue-Tek in liquid nitrogen and stored at $-70 /-80^{\circ} \mathrm{C}$. Sections $(7 \mu \mathrm{m})$ were cut on a freezing microtome and mounted on 3-aminopropyl triethoxy silane coated slides. Sections were fixed with dry acetone for 7 minutes, air dried, and preincubated for 20 minutes in $10 \%$ normal horse serum and $10 \%$ normal human serum in phosphate buffered saline (PBS). Sections were incubated with primary antibodies diluted in PBS with $1 \%$ normal horse serum/normal human serum for 60 minutes. Murine monoclonal antibodies for IFN $\gamma$ (MD-2; Holland Biotechnology, Rijswijk, the Netherlands) and IL4 (1-4l-1; Novartis, Basel Switzerland) were used. ${ }^{11}$ Slides were washed three times for 5 minutes with PBS+0.05\% Tween 20, after which a second incubation of biotinylated horse-antimouse antibody was applied for 30 minutes. After washing with PBS/Tween the sections were incubated with streptavidin conjugated alkaline phosphatase for 30 minutes and washed in Tris-HCl. Alkaline phosphatase activity was demonstrated with ASbiphosphate as substrate and new fuchsin as chromogen dissolved in $0.1 \mathrm{M}$ Tris- $\mathrm{HCl}, \mathrm{pH} 8.5$, resulting in pink/red staining. Endogenous alkaline phosphatase activity was inhibited by addition of levamisole to the reaction mixture. The entire procedure without the first antibodies served as control and did not show any staining. Slides were slightly counterstained thereafter with haematoxylin and embedded in gelatin.

Salivary gland INF $\gamma$ and IL4 positive cells were counted by two independent observers ( $\mathrm{JM} v \mathrm{vW}$ and MJG WvW) in 12 subsequent designated areas of $0.04 \mathrm{~mm}^{2}$ in each biopsy
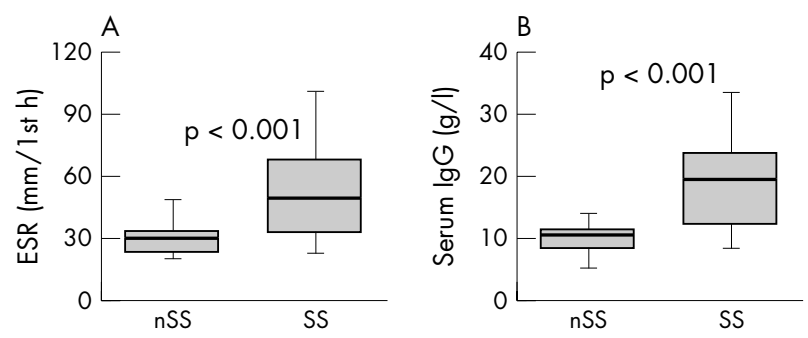

Figure 1 ESR and serum lgG of 30 patients with nSS-sicca and 32 patients with SS. The solid line represents the median value, the boxes stretch from the lower 25th centile to the upper 75th centile. Values of $p$ for differences between the SS and non-SS sicca patient groups are given. specimen. Neither of the observers knew the patients' identity and the monoclonal antibody used.

\section{Peripheral Th 1 and Th2 cell activity}

From all patients, PB was diluted 1:1 with Dulbecco's modified Eagle's medium (DMEM; Gibco 074-01600, Gibco, Paisley, UK). Thereafter, mononuclear cells were isolated by density centrifugation using Ficoll-Paque (Pharmacia Biotech, Roosendaal, The Netherlands). Isolated cells $\left(5 \times 10^{5} / \mathrm{ml}\right)$ were cultured for 48 hours in DMEM supplemented with penicillin $(100 \mathrm{U} / \mathrm{ml})$, streptomycin sulphate $(100 \mu \mathrm{g} / \mathrm{ml})$, glutamine $(2 \mathrm{mmol} / \mathrm{l})$, and $10 \%$ human pooled adult blood group $\mathrm{AB}^{+}$serum. T cell-specific cytokine production was amplified by adding CD3 and CD28 monoclonal antibodies (CLB, Amsterdam, The Netherlands; $1.5 \mu \mathrm{g} /$ $\mathrm{ml}$ and $2 \mu \mathrm{g} / \mathrm{ml}$, respectively). ${ }^{12}$ After 48 hours of ex vivo culture, ${ }^{10}$, the culture media were harvested, rendered cellfree by centrifugation, frozen in liquid nitrogen, and stored at $-20^{\circ} \mathrm{C}$. IFN $\gamma$ and IL4 levels were determined by enzyme linked immunosorbent assay (ELISA) according to the manufacturer's instructions (Biosource, Etten-Leur, The Netherlands). Detection limits of the assays were $10 \mathrm{pg} / \mathrm{ml}$ for both IFN $\gamma$ and IL4.

\section{Th $1 /$ Th 2 cell activity and extraglandular manifestations, autoantibodies, and SG infiltration in the pSS group}

For the 26 patients with pSS, PB IFN $\gamma$ and IL4 production as well as SG IL4+ and IFN $\gamma+$ cell numbers were compared in patients with $(\mathrm{n}=12)$ and without $(\mathrm{n}=14)$ extraglandular manifestations (cytopenia, arthritis, neuropathy, leucocytoclastic vasculitis, other skin lesions), antinuclear antibodies $(\mathrm{n}=20 \vee 6$, respectively), anti-Ro/SS-A $(\mathrm{n}=21 \vee 5)$, and antiLa/SS-B antibodies $(n=10 v 16)$. In addition, within the pSS group the grade of SG infiltration expressed by the lymphocytic focus score (ranging from 0 to 6 foci $/ 4 \mathrm{~mm}^{2} \mathrm{SG}$ tissue) was correlated with the cytokine profiles in PB and SG.

\section{Statistical analysis}

None of the parameters, including ESR, serum IgG, number of cytokine positive cells in the SGs, and cytokine production by PB T cells, were normally distributed. Differences between patients with SS and nSS-sicca were therefore expressed as box plots representing medians and $25 \%$ and $75 \%$ centiles, and analysed by the Mann-Whitney $U$ test (two tailed). For correlations, data were transformed to a logarithmic (ln) scale, resulting in a normal distribution and, subsequently, Pearson analysis was performed. Differences between patients with pSS with or without extraglandular manifestations and autoantibodies were also analysed by the Mann-Whitney U test. Spearman's correlation coefficients were calculated to relate SG infiltration in the pSS group with cytokine profiles. Values of $\mathrm{p}<0.05$ were considered significant.

\section{RESULTS}

Differences in parameters between patients with SS and patients with $\mathrm{nSS}$-sicca

Figure 1 shows that significant differences in mean ESR and serum IgG levels existed between patients with nSS-sicca and those with SS. Although a clear difference was found, a significant overlap was seen for both measures between both patients groups (see also figs 3-5).

The number of IFN $\gamma+$ cells in the SG (fig 2A) was significantly higher in the SS group than in the nSS-sicca group. No such difference was found for the numbers of IL4+ cells in the SG (fig 2B). IFN $\gamma$ production by PB T cells from patients with SS (fig 2D) was significantly lower than that of patients with nSS-sicca. In PB, for Th2 cell activity also, no such differences were found (fig 2E). 

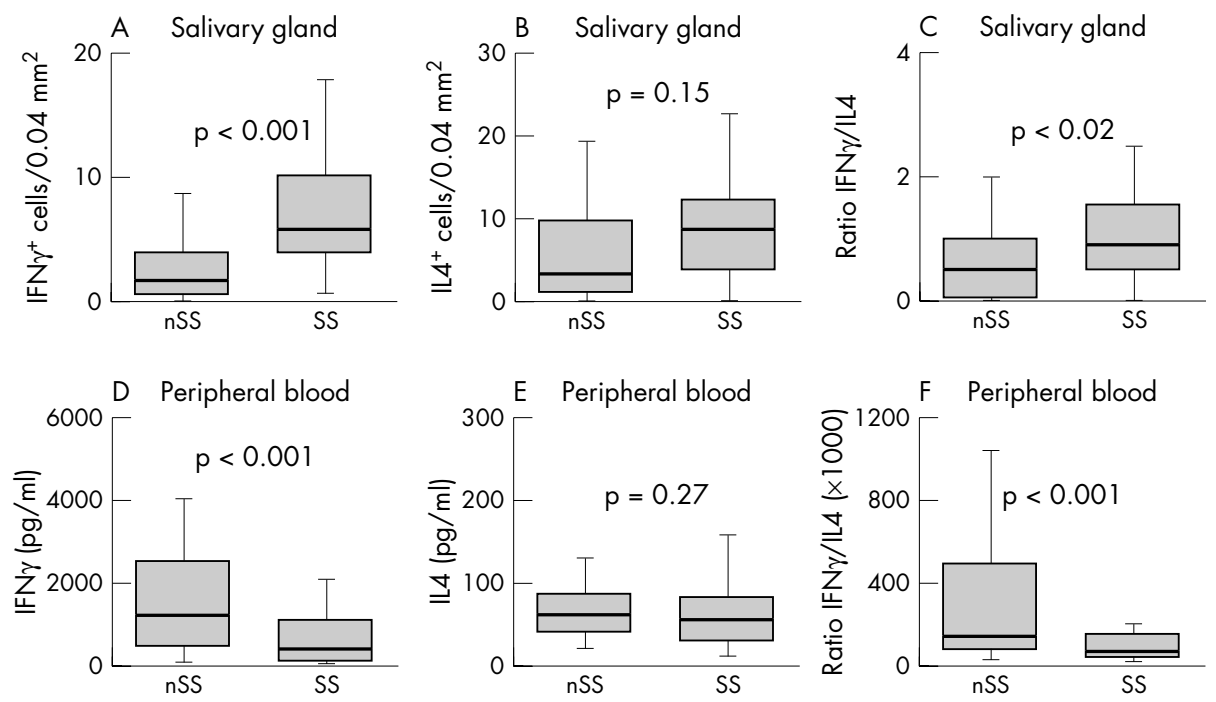

Figure 2 SG and PB cytokine profile for patients with $n S S$-sicca and $S S$ ( $n=30$ and 32 patients, respectively). The solid line represents the median value, the boxes stretch from the lower 25 th centile to the upper 75 th centile. (A, B, C) SG number of IFN $\gamma$ (A) and IL4 (B) positive cells $/ 0.04 \mathrm{~mm}^{2}$ and the ratio IFN $\gamma /$ IL4 positive T cells (C). (D, E, F) PB ex vivo IFN $\gamma$ (D), IL4 (E), and the ratio IFN $\gamma /$ IL4 production ( $\times 1000 ; F)$ for the SS and non-SS sicca patient groups. Values of $\mathrm{p}$ for differences between SS and non-SS sicca patient groups are given.

In SGs the ratio of IFN $\gamma+/$ IL4+ cells was higher in the patients with SS than in the patients with nSS-sicca (fig 2C), but in PB the opposite was found (fig $2 \mathrm{~F}$ ).

None of the measures in either of the two compartments conclusively discriminated between SS and nSS-sicca in individual patients (see also figs 3-5).

\section{Correlations between Th $1 /$ Th2 cell activity and disease activity measures}

In the whole sicca population (patients with SS plus those with nSS-sicca) the number of IFN $\gamma+$ cells in the SGs correlated positively with the ESR and serum IgG (figs $3 \mathrm{~A}$ and $\mathrm{B}$, respectively). Moreover, for $\mathrm{PB}$, a negative correlation
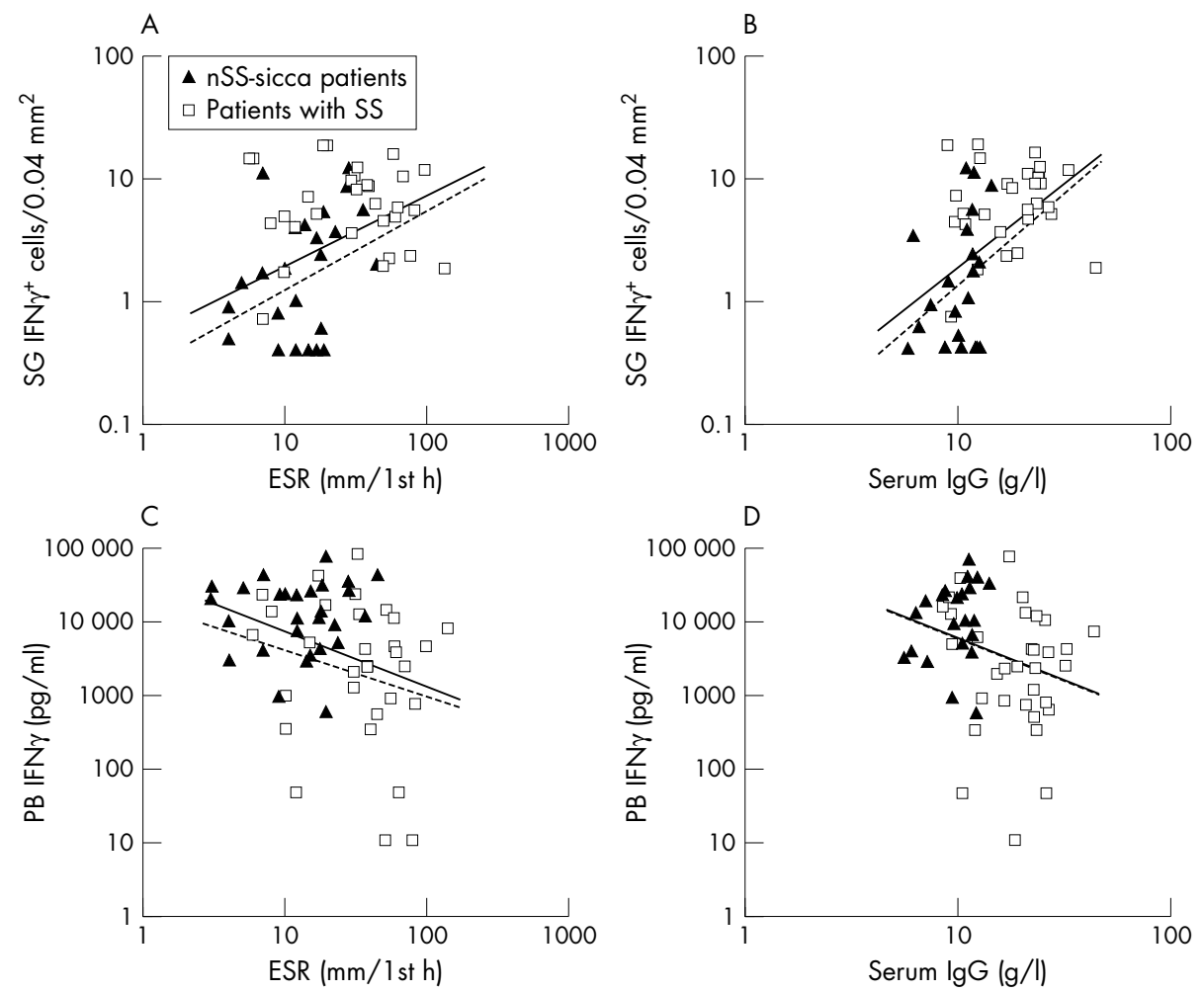

Figure 3 Relations between measures of disease activity and IFN $\gamma$ profiles. (A, B) depict the relation between SG IFN $\gamma+\mathrm{T}$ cells $\left(\mathrm{number} / 0.04 \mathrm{~mm}{ }^{2}\right.$ ) and ESR (A) and serum IgG (B). (C, D) depict the relation between PB T cell IFN $\gamma$ production $(\mathrm{pg} / \mathrm{ml})$ and ESR (C) and serum lgG (D). Pearson correlations with logarithmic transformed data (to obtain a normal distribution) have been performed. Regression lines for the correlations in the whole sicca group are given by the (solid) lines. The dotted lines represent regression lines for the correlations in the nSS-sicca groups in (A) and (B) and the SS group in (C; see table 1 for details). 
Table 1 Correlations between Th1 (IFN $\gamma$ ) and Th2 (IL4) cell activity and parameters of disease activity (ESR and serum lgG) in salivary glands (SG) and peripheral blood (PB) in the whole sicca group, the patients with SS and nSS-sicca groups (see also figures 3-5)

\begin{tabular}{|c|c|c|c|c|c|c|c|c|c|c|c|c|}
\hline \multirow{2}{*}{ IFN $\gamma($ fig 3) } & \multicolumn{6}{|l|}{ ESR } & \multicolumn{6}{|c|}{ Serum IgG } \\
\hline & \multicolumn{2}{|c|}{ Whole group } & \multicolumn{2}{|l|}{ nSS } & & SS & \multicolumn{2}{|c|}{ Whole group } & \multicolumn{2}{|l|}{ nSS } & \multicolumn{2}{|l|}{ SS } \\
\hline $\begin{array}{l}\text { SG } \\
\text { PB }\end{array}$ & $\begin{array}{l}0.41 \\
-0.32\end{array}$ & $\begin{array}{l}(0.00) \\
(0.01)\end{array}$ & $\begin{array}{l}0.34 \\
\text { NS }\end{array}$ & (0.05) & $\begin{array}{l}\text { NS } \\
-0.20\end{array}$ & (0.14) & $\begin{array}{l}0.49 \\
-0.28\end{array}$ & $\begin{array}{l}(0.00) \\
(0.04)\end{array}$ & $\begin{array}{l}0.30 \\
\text { NS }\end{array}$ & (0.09) & $\begin{array}{l}\text { NS } \\
\text { NS }\end{array}$ & \\
\hline $\begin{array}{c}\text { IL4 (fig 4) } \\
\text { SG } \\
\text { PB }\end{array}$ & $\begin{array}{l}\text { NS } \\
\text { NS }\end{array}$ & & $\begin{array}{l}0.24 \\
\text { NS }\end{array}$ & $(0.12)$ & $\begin{array}{l}\text { NS } \\
\text { NS }\end{array}$ & & $\begin{array}{l}0.31 \\
-0.25\end{array}$ & $\begin{array}{l}(0.03) \\
(0.07)\end{array}$ & $\begin{array}{l}0.51 \\
-0.31\end{array}$ & $\begin{array}{l}(0.01) \\
(0.08)\end{array}$ & $\begin{array}{l}\text { NS } \\
\text { NS }\end{array}$ & \\
\hline $\begin{array}{l}\text { IFN } \gamma / \text { IL4 (fig } \\
\text { SG } \\
\text { PB }\end{array}$ & $\begin{array}{l}0.17 \\
-0.38\end{array}$ & $\begin{array}{l}(0.11) \\
(0.00)\end{array}$ & $\begin{array}{l}\text { NS } \\
\text { NS }\end{array}$ & & $\begin{array}{l}\text { NS } \\
-0.33\end{array}$ & (0.04) & $\begin{array}{l}0.28 \\
-0.32\end{array}$ & $\begin{array}{l}(0.03) \\
(0.01)\end{array}$ & $\begin{array}{l}\text { NS } \\
0.38\end{array}$ & (0.04) & $\begin{array}{l}\text { NS } \\
-0.24\end{array}$ & $(0.11)$ \\
\hline
\end{tabular}

Correlation coefficients with $p$ values (between brackets) when significance was neared or reached-that is, with $p$ values $\leqslant 0.15$. Regression lines in cases of significance have been drawn in figs 3,4 , and 5, respectively.

between IFN $\gamma$ production and ESR and serum IgG was found (figs $3 \mathrm{C}$ and D) in the whole group. For the subgroups (SS and nSS-sicca) several similar positive and negative correlations were found for the local and peripheral compartments, respectively (table 1 and dotted lines in fig 3 ). However, because of the relatively small numbers in both subgroups, only three of eight correlations neared or reached statistical significance. Importantly, no significant opposite correlations for the subgroups were found, when compared with the whole group.

SG IL4 (fig 4B) correlated positively with serum IgG but not with ESR (fig 4A). PB IL4 correlated negatively with serum IgG (fig 4D), but again not with ESR (fig 4C). Also for the subgroups (SS and nSS-sicca) several almost identical correlations were found (fig 4, dotted lines; table 1). No significant opposite correlations were found.

The salivary gland IFN $\gamma+/ \mathrm{IL} 4+$ cell ratio in the whole sicca population showed a positive correlation with ESR ( fig 5A) and serum IgG (fig 5B), although not statistically significant for ESR. In PB a negative correlation was found for the ratio IFN $\gamma /$ IL4 production with ESR (fig 5C) and with serum IgG (fig 5D). Also for the subgroups (SS and nSS-sicca) several almost identical correlations were found (fig 5, dotted lines; table 1); no significant opposite correlations were found, with one exception: for the nSS-sicca group the ratio IFN $\gamma /$ IL4 correlated positively with $\operatorname{IgG}\left(r_{\mathrm{s}}=+0.38, \mathrm{p}=0.04\right.$, see table 1$)$.
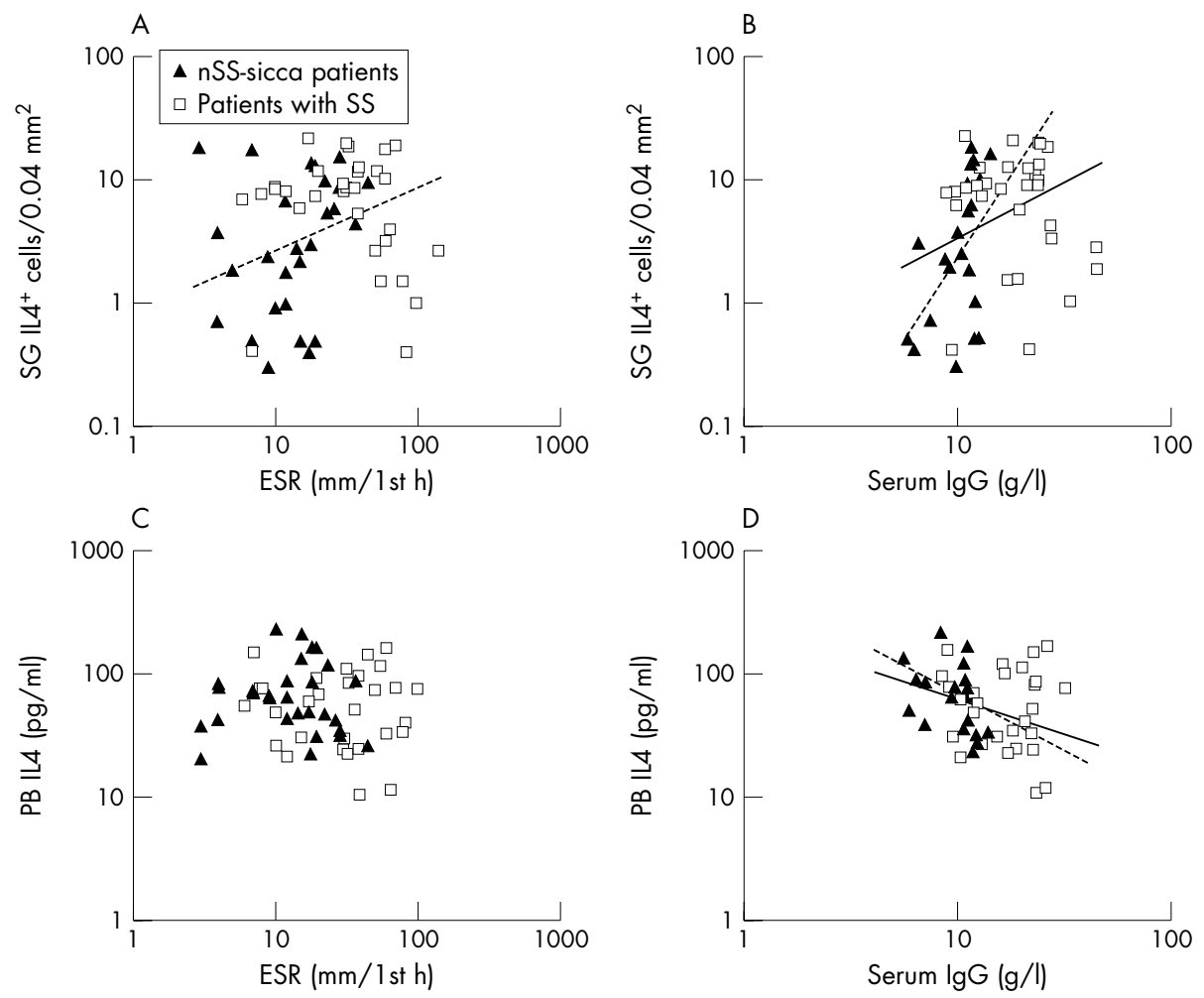

Figure 4 Relations between measures of disease activity and IL4 profiles. (A, B) depict the relation between SG IL4+ T cells $\left(\right.$ number $\left./ 0.04 \mathrm{~mm}^{2}\right)$ and ESR (A) and serum lgG (B). (C, D) depict the relation between PB T cell IL4 production (pg/ml) and ESR (C) and serum lgG (D). Pearson correlations with logarithmic transformed data (to obtain a normal distribution) have been performed. Regression lines for the correlations in the whole sicca group are given by the (solid) lines. The dotted lines represent regression lines for correlations in the nSS-sicca group in (A), (B), and (D; see table 1 for details). 

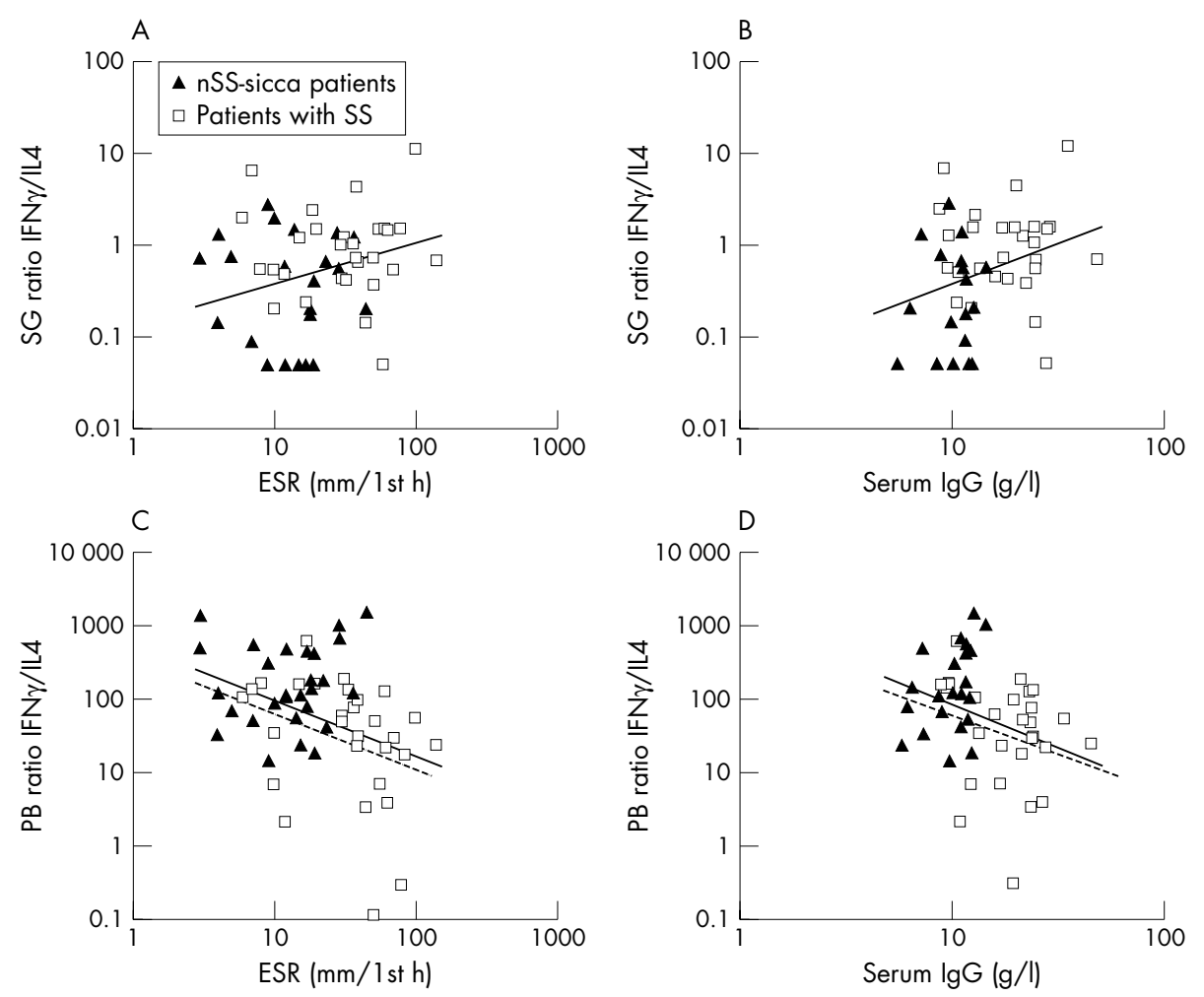

Figure 5 Cytokine ratio profiles related to measures of disease activity. (A, B) depict the relation of SG IFN $\gamma /$ IL4 positive T cells with ESR (A) and serum $\lg G(B)$. (C, D) depict the relation of PB T cell IFN $\gamma /$ IL4 production $(\times 1000)$ with ESR (C) and serum IgG (D). Pearson correlations with logarithmic transformed data (to obtain a normal distribution) have been performed. Regression lines for the correlations in the whole sicca group are given by the (solid) lines. The dotted lines represent regression lines for the correlations in the SS group in (C) and (D; see table 1 for details).

\section{Local Th $1 /$ Th 2 cell activity related to peripheral Th $1 /$ Th2 cell activity}

The difference in the Th1/Th2 ratio between SGs (high for the SS group, low for the nSS-sicca group) and PB (low for the SS group, high for the nSS-sicca group) (see fig 2) suggests a negative relation between local and peripheral Thl and Th2 cell activity. However, no significant correlations between local and peripheral cytokine profiles were found in the whole sicca population or subgroups, either for the individual cytokines or for the ratios (data not shown).

\section{Th 1 /Th 2 cell activity and extraglandular manifestations, autoantibodies, and SG infiltration in the pSS group}

In the pSS group, no differences were found between patients with and without extraglandular manifestations, antinuclear antibodies, anti-Ro/SS-A and anti-La/SS-B autoantibodies in PB IFN $\gamma$ and IL4 production or in SG IFN $\gamma+$ and IL4+ cell numbers. Neither did the lymphocytic focus score correlate with PB or SG Th1 or Th2 profiles (data not shown).

\section{DISCUSSION}

Over the past 10 years evidence has accumulated suggesting that a Th1/Th2 imbalance has a role in the pathogenesis of SS. ${ }^{6-9}{ }^{13}$ The present study is unique in that it analysed Thl and Th2 profiles, local versus peripheral (in a paired set-up), in patients with SS versus patients with nSS-sicca related to serum IgG as well as ESR using a significant number of patients and using detection of actual protein. We found that Thl cell activity was high at the site of inflammation (SGs) and low in PB when patients with SS were compared with patients with nSS-sicca. However, neither local nor peripheral Thl activity discriminated between patients with SS and those with nSS-sicca. This is in agreement with a report from Konttinen et al, ${ }^{14}$ in which production of classical Thl cytokines also in normal glands was described. Therefore, there seems to be no rationale for determining local or peripheral Thl activity in the individual sicca patient for diagnostic purposes. Moreover, although patients with SS had higher ESR and serum IgG values than patients with nSS-sicca, both patient groups also demonstrated a considerable overlap for these two measures. From a clinical point of view this is interesting because high serum IgG levels in patients with nSS-sicca have been reported to predict the development of SS. ${ }^{2}$

In the whole sicca group the number of IFN $\gamma+$ cells, the ratio IFN $\gamma+/$ IL4+ cells, and also the number of IL4+ cells in the SG correlated positively with measures of disease activity. The opposite was found for PB: IFN $\gamma$ and the ratio IFN $\gamma / \mathrm{IL} 4$, and also IL4 correlated negatively with disease activity measures. This demonstrates that the differences between local and peripheral Th1 and Th2 cell activity are most pronounced for Thl cell activity, but similar, although less prominent, for Th2 cell activity. High local Thl activity in SS might be insufficiently counterregulated by a Th2 response. It is tempting to suggest that in patients with SS, Th cells from the PB (mostly Thl cells but also Th2 cells) have migrated to the SGs, and that this phenomenon depends on, or possibly predicts, the severity of the disease. In analogy with the present data, in patients with RA (compared with healthy controls) low Thl activity in PB and high intra-articular Thl activity have been found. ${ }^{15}{ }^{16}$ However, the lack of correlation between local Thl profiles and lymphocytic focus scores seen in this study does not support this hypothesis. Moreover, the absence of a (positive or negative) correlation between local and peripheral Th cell activity suggests that peripheral Th cell 
activity is not simply a reflection of local Th cell activity, but may also represent the systemic autoimmune response observed in SS.

Although far from conclusive, the present data strongly suggest that patients with nSS-sicca might, at least in some cases, represent SS, although not fulfilling the classification criteria. On the other hand it might be that a relevant number of patients are undeservedly classified as patients with SS, whereas others who may actually have SS are missed. Whether the latter group only represent a milder form of SS or whether we are dealing with a pre-phase of SS, as has been suggested, ${ }^{2}$ cannot be confirmed and certainly requires additional study.

The peripheral shortage of Thl cytokine production might suggest possibilities of therapeutic strategies of systemic Thl cell cytokine supplementation against disease as suggested by Hagiwara et al. ${ }^{8}$ However, in the light of the mechanisms depicted above, and the observed low peripheral IL4 production correlating with serum IgG levels, more study is needed before such approaches can be realised.

In conclusion, ESR, serum IgG, or local or peripheral Thl and Th2 cell activity did not discriminate between patients with SS and those with nSS-sicca; both groups have at least some common characteristics. The increased local Thl cell activity correlating with more severe immune dysregulation in sicca patients (ESR and serum IgG) might not be overcome by an adequate local Th2 cell response. This imbalance may be partially responsible for the perpetuation of the immune response in SS. Studies in SS that evaluate therapeutic agents which shift the balance towards local Th2 cell activity might be considered and studied.

\section{Authors' affiliations}

J M van Woerkom, A A Kruize, M J G Wenting - van Wijk, J W G Jacobs, J W J Biilsma, F P J G Lafeber, J A G van Roon, Department of Rheumatology and Clinical Immunology, University Medical Centre Utrecht, The Netherlands

E Knol, I C Bihari, Department of Dermatology/Allergology, University Medical Centre Utrecht, The Netherlands

\section{REFERENCES}

1 Kruize AA, Hene RJ, van der Heide A, Bodeutsch C, de Wilde PC, van Bijsterveld 'OP, et al. Long-term followup of patients with Siögren's syndrome. Arthritis Rheum 1996;39:297-303.

2 Pertovaara M, Korpela M, Uusitalo H, Pukander J, Miettinen A, Helin H, et al. Clinical follow up study of 87 patients with sicca symptoms (dryness of eyes or mouth, or both). Ann Rheum Dis 1999:58:423-7.

3 Skopouli FN, Fox PC, Galanopoulou V, Atkinson JC, Jaffe ES, Moutsopoulos HM. T cell subpopulations in the labial minor salivary gland histopathologic lesion of Sjögren's syndrome. J Rheumatol 1991;18:210-14.

4 Romagnani S. Lymphokine production by human T cells in disease states. Annu Rev Immunol 1994; 12:227-57.

5 Mosmann TR, Sad S. The expanding universe of T-cell subsets: Th1, Th2 and more. Immunol Today 1996;17:138-46

6 Ohyama Y, Nakamura S, Matsuzaki G, Shinohara M, Hiroki A, Fujimura T, et al. Cytokine messenger RNA expression in the labial salivary glands of patients with Siögren's syndrome. Arthritis Rheum 1996;39:1376-84.

7 Mitsias DI, Tzioufas AG, Veiopoulou C, Zintzaras E, Tassios IK, Kogopoulou $O$, et al. The Th1/Th2 cytokine balance changes with the progress of the immunopathological lesion of Sjögren's syndrome. Clin Exp Immunol 2002;128:562-8.

8 Hagiwara E, Pando J, Ishigatsubo Y, Klinman DM. Altered frequency of type 1 cytokine secreting cells in the peripheral blood of patients with primary Siögren's syndrome. J Rheumatol 1998;25:89-93.

9 Kohriyama K, Katayama Y. Disproportion of helper T cell subsets in peripheral blood of patients with primary Siögren's syndrome. Autoimmunity 2000;32:67-72.

10 Vitali C, Bombardieri S, Jonsson R, Moutsopoulos HM, Alexander EL, Carsons SE, et al. Classification criteria for Sjögren's syndrome: a revised version of the European criteria proposed by the American-European Consensus Group. Ann Rheum Dis 2002;61:554-8.

11 Thepen T, Langeveld-Wildschut EG, Bihari IC, van Wichen DF, van Reijsen FC, Mudde GC, et al. Biphasic response against aeroallergen in atopic dermatitis showing a switch from an initial $\mathrm{TH} 2$ response to a $\mathrm{TH} 1$ response in situ: an immunocytochemical study. J Allergy Clin Immunol 1996:97:828-37.

12 Verhoef CM, Van Roon JA, Vianen ME, Glaudemans CA, Lafeber FP, Bijlsma JW. Lymphocyte stimulation by CD3-CD28 enables detection of low T cell interferon-gamma and interleukin-4 production in rheumatoid arthritis. Scand J Immunol 1999:50:427-32.

13 Fox RI, Kang HI, Ando D, Abrams J, Pisa E. Cytokine mRNA expression in salivary gland biopsies of Sjögren's syndrome. J Immunol 1994; 152:5532-9.

14 Konttinen YT, Kemppinen P, Koski H, Li TF, Jumppanen M, Hietanen J, et al. $T(H) 1$ cytokines are produced in labial salivary glands in Siögren's syndrome, but also in healthy individuals. Scand J Rheumatol 1999;28:106-12.

15 Morita Y, Yamamura M, Kawashima M, Harada S, Tsuji K, Shibuya K, et al. Flow cytometric single-cell analysis of cytokine production by CD4+T cells in synovial tissue and peripheral blood from patients with rheumatoid arthritis. Arthritis Rheum 1998:41:1669-76.

16 Van Roon JA, Verhoef CM, van Roy JL, Gmelig-Meyling FH, Huber-Bruning O, Lafeber FP, et al. Decrease in peripheral type 1 over type $2 \mathrm{~T}$ cell cytokine production in patients with rheumatoid arthritis correlates with an increase in severity of disease. Ann Rheum Dis 1997;56:656-60. 